\title{
A review of zoanthid nematocyst types and their population structure
}

\author{
J. S. Ryland* \& J. E. Lancaster \\ University of Wales Swansea, Swansea SA2 8PP, UK \\ (*Author for correspondence: E-mail: j.s.ryland@swan.ac.uk)
}

Key words: Cnidaria, Hexacorallia, Palythoa, Protopalythoa, cnidae, capsules, discriminant analysis

\begin{abstract}
Seven different types of nematocyst are detailed and illustrated from the Zoanthidea. We studied the size population structure of nematocyst capsules: how they are affected by preservation, and how and what should be measured. Populations of two types, large holotrichs and $p$-mastigophores, from the mesenterial filaments of Protopalythoa heliodiscus and Pr. mutuki have been compared using length, width, and (for $p$-mastigophores) shaft length. The analysis employed bivariate scattergrams and discriminant analysis. The two species are strongly differentiated by their holotrichs, less well by their $p$-mastigophores. The problem of bimodal size distributions is considered and resolved. It is recommended that nematocyst capsule population descriptors should always be included in species' descriptions, in addition to or instead of the customary minimum-maximum range.
\end{abstract}

\section{Introduction}

The presence of cnidae is one of the defining characteristics of the phylum Cnidaria. Within the Anthozoa, the types, characteristics, and capsule dimensions of one category of cnidae, the nematocysts, have been used in systematics for a century (Fautin, 1988), but the most appropriate data for species discrimination and higher level taxonomy remain open to debate. In this paper we first review the types of nematocyst recorded in Zoanthidea, updating the surveys of Schmidt (1972, 1974), and then explore the use of quantitative data, following the procedural recommendations recently formulated (Ryland et al., 2003). For recognition of nematocyst types, of which at least seven are known for Zoanthidea (Fig. 1), we follow Schmidt (1972, 1974), because of his clear diagrams (Fig. 1), but prefer a terminology based on that of Weill (1934). The first group of types comprises: large holotrichs (holotrichs I of Schmidt) or holotrichous isorhizas (i.e. with parallel sided tubule; Fig. 1D); small holotrichs (holotrichs II) which, from Schmidt's depiction of a tapering tubule, appear to be holotrichous anisorhizas (Fig. 1B and C); and large atrichs - not included by Schmidt in the zoanthid assemblage although they had been recorded from the order by Cutress (1955) (Fig. 1A) and are present in the Actiniaria, from one division of which (Endomyaria) Schmidt (1974) derived the Zoanthidea. The second group comprises the various mastigophores: nematocysts with slender elongate capsules which, following England (1991) - who broadened Weill's (1934) original description to include mastigophores in which the shaft is wider, but only slightly wider, than the rest of the tubule - we identify as basitrichs (Fig. 1E and F; microbasic $b$-rhabdoids of Schmidt); $p$-mastigophores ( $p$-rhabdoids of Schmidt), with a wide, sharply defined shaft (Fig. 1G); and microbasic $b$-mastigophores sensu stricto (special $b$-rhabdoids of Schmidt; Fig. 1H) which, in zoanthids, are more ovoid and less fusiform than basitrichs, and which - according to Schmidt (1974) - are restricted to the 'higher' Zoanthidea (a term of his own which 


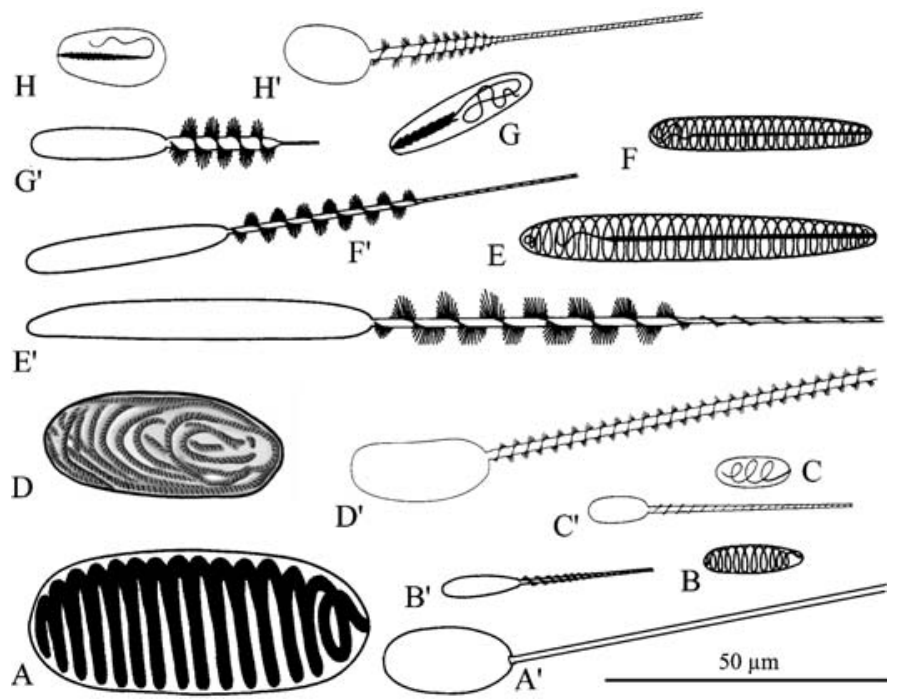

Figure 1. The types of nematocyst found in zoanthids. (A, A') Atrich, Palythoa caesia. (B, B') Small holotrich (holotrich II), Palythoa tuberculosa. (C, C') Small holotrich, Parazoanthus axinellae. (D, D') Large holotrich (holotrich I), Palythoa caesia. (E, E') Large basitrich, Palythoa tuberculosa. (F, F') Medium basitrich, Palythoa tuberculosa (a form with a short shaft occurs in Parazoanthus axinellae). (G, G') Microbasic $p$-mastigophore, Palythoa tuberculosa. $\left(\mathrm{H}, \mathrm{H}^{\prime}\right)$ Microbasic $b$-mastigophores, Parazoanthus axinellae $(\mathrm{H})$, Zoanthus coppingeri $=$ pacificus $\left(\mathrm{H}^{\prime}\right)$. Except $\mathrm{A}^{\prime}$ and $\mathrm{D}$, from Schmidt (1974).

we equate with all the Macrocnemina plus part (family Zoanthidae sensu stricto) of the Brachycnemina (see Ryland et al., 2003, for discussion). Schmidt evidently perceived these 'special' $b$-mastigophores as different from those of anemones.

To a small extent, higher anthozoan taxa may be characterized by their types of cnidae, as Hexacorallia are by spirocysts and Ceriantharia by ptychocysts. Carlgren (1940) believed that Ceriantharia were also characterized by lacking $p$-mastigophores, but they are present in arachnactis larvae (Schmidt, 1974). Schmidt considered that zoanthid holotrichs differed from those of all other orders in having 'spoon-shaped' spines, and that 'special' $b$-mastigophores were unique to 'higher' Zoanthidea. Certainly, we have not seen these $b$-mastigophores in the Sphenopidae (equivalent to Schmidt's 'lower' Zoanthidea) which are, however, the only zoanthids to have large basitrichs - of the type prevalent in Endomyaria - in the filaments.

In a comprehensive study of the cnidom of one zoanthid, Acrozoanthus australiae (Brachycnemina Zoanthidae), Ryland et al. (2003) demonstrated the scope for error if species' nematocyst capsule sizes are expressed solely as a range between observed upper and lower limits based on a sample of, say, $n=20$. We investigated the practicalities of using standard statistical procedures to describe nematocyst samples representing populations (as by Hidaka, 1992; Pires \& Pitombo, 1992; Chintiroglou \& Simsiridou, 1997), rather as done for anemones by Williams $(1996,1998,2000)$ but not always reaching the same conclusions. However, there are obvious limitations to the utility of conclusions based on a single species, and we here consider some data from species of Brachycnemina Sphenopidae (Schmidt's, 1974 'lower' Zoanthidea).

\section{Material and methods}

For a few specimens, at the Australian Institute for Marine Science (AIMS), fresh nematocysts were obtained as aqueous squashes of fragments of tentacles and filaments. Discharge was encouraged with a drop of acetic acid and pressure on a cover slip, and the preparation viewed under Nomarski illumination. Photomicrographs were taken on colour film, using a $\times 40$ objective and $\times 3.3$ or $\times 5$ photo-ocular; the camera automatically imprinted a scale. Measurements were made from the film, as below. 
Later, preserved zoanthids fixed in seawater formalin (4\% HCHO), Bouin's fluid, or $70 \%$ ethanol were used. After dab drying, since polyp size may be an important variable, volume was determined by displacement (all methods being described in more detail by Ryland et al. (2003)). Using a dissecting microscope, minute amounts of tissue were removed from filaments using extrafine jewellers' forceps. The tissue was digested for 2-3 min in a few drops of $2 \%$ aqueous $\mathrm{KMnO}_{4}$ on a microscope slide, excess fluid absorbed with a strip of filter paper, a drop of glycerol added, and the preparation macerated with the forceps (the method modified from England (1987)). The fragmented cells were spread by light, even pressure on the cover slip, $22 \times 22 \mathrm{~mm}$, which was then ringed with clear nail varnish to prevent evaporation.

Slides were systematically scanned for nematocyst capsules from the top left to the bottom right of the coverslip. All capsules lying wholly in the focal plane were measured; capsules oblique to the focal plane, being foreshortened, were ignored. When available, 100 capsule measurements were made of length, width and, for $p$-mastigophores, shaft length using bright-field or phase contrast illumination and $\times 40$ objectives. Except in the case of the freshly obtained holotrich/atrich sample, we have not used results when $n<20$. A video camera attached via a $\times 6.7$ photo-ocular fed images to a dedicated image-analysis computer. Following calibration, measurements in $\mu \mathrm{m}$ were made on the screen image. The excellent but now obsolete DOS software MeasurementTV (Updegraff, 1990) was used at the time; we currently use Image-Pro Plus. Original basic statistics were performed in Quattro-Pro, later transferred to MS Excel ${ }^{\circledR} 2000$ with XLstat add-in (Fahmy \& Aubry, 2002) or BIOMstat 3.3 (Rohlf \& Slice, 2002) for ANOVA.

\section{Results}

When freshly discharged nematocysts from the filaments of Palythoa caesia Dana were examined, it was observed that the large, oblong-oval (in plan view) capsules had discharged two different types of tubule. In one, the tubule was wide, $\sim 4.5 \mu \mathrm{m}$, with large spines arranged in a triple helix.
Undischarged, the tubule was loosely and obliquely coiled, in the manner of a vertical coil of rope that has been pulled sideways from the top, with the spines producing a banded appearance under Nomarski illumination (Fig. 1D). This type corresponded to Schmidt's (1974) holotrich I, described from $P a$. tuberculosa, although he illustrates the spines in a single helix (Fig. 1D'). In the second type (despite the larger capsule, see below) the tubule was thinner, $\sim 3.7 \mu \mathrm{m}$, and appeared totally devoid of spines, even when using a $\times 100$ oil immersion objective; prior to discharge the tubule was coiled in the capsule like a spring (Fig. 1A and $\left.A^{\prime}\right)$ - very different from the holotrichs. It corresponded with the atrich described by Schmidt (1974) in actinians but not recorded by him in $\mathrm{Pa}$. tuberculosa or any other zoanthid, although he had evidently overlooked that Cutress (1955) had mentioned them from unspecified zoanthids as well as actinians. Our specimens matched Cutress' description perfectly. The holotrich and atrich capsules were also readily separated by size and shape: holotrichs $(n=4) \quad$ length 61.18 $(\mathrm{SD} \pm 2.59) \mu \mathrm{m}$, width $26.85( \pm 1.66) \mu \mathrm{m}$, ratio $2.28( \pm 0.05) ;$ atrichs $(n=10)$ length 82.80 $( \pm 2.93) \mu \mathrm{m}$, width $34.02( \pm 4.55) \mu \mathrm{m}$, ratio 2.47 $( \pm 0.29)$. In a much larger, preserved sample $(n=100)$ of holotrichs the dimensions were 62.29 $( \pm 2.78) \times 28.60( \pm 2.08) \mu \mathrm{m}$; no atrichs were present. We retain the term atrich, since no spines are visible under the light microscope, though aware that Westfall (1965) - using transmission electron microscopy - could identify small spines around the tubule in the atrichs of Metridium.

Photographs were also taken of discharged and undischarged basitrichs and $p$-mastigophores of Protopalythoa mutuki Haddon \& Shackleton from the rocky shore at Kissing Point, Townsville, for later comparison with preserved material. Using measurements from the film we compared discharged and undischarged basitrichs by ANOVA, the mean lengths being not significantly different: means $( \pm \mathrm{SD})$ undischarged $57.69( \pm 3.68)$, discharged $56.70( \pm 3.68), p \approx 0.2$, but width had slightly increased: undischarged $6.69( \pm 1.00)$, discharged $7.12( \pm 0.89), p=0.045$. Three methods of fixation were compared: sea water Bouin's fluid for $48 \mathrm{~h}$ or more followed by washing and storage in $70 \%$ ethanol, direct immersion in $70 \%$ ethanol, and $4 \%$ formaldehyde in sea water 
(though later samples were washed and transferred to $70 \%$ ethanol). The dimensions for basitrichs, holotrichs, and p-mastigophores are in Table 1. While the long, slender basitrichs (Fig. 1E and F) may perhaps be adequately characterized by length, $p$-mastigophores are quite oval in plan view and holotrichs are oblong-oval (Fig. 1G and D respectively). We have, therefore, measured both length and width. ANOVA of preserved basitrich lengths showed significant differences $\left(p=2.67 \times 10^{-9}\right)$, with a similar (though less pronounced, $p=0.003-0.0001$ ) result for length and width together using XLstat for discriminant analysis. Moreover, when measurements of fresh undischarged and exploded basitrichs were included, the differences were even more marked $(p<0.0001$ in all tests). For clarity in the diagram, all the preserved samples have been combined (Fig. 2). On holotrich lengths the corresponding ANOVA was significant $\left(p=6.54 \times 10^{-6}\right)$ but discriminant analysis of lengths and widths gave mixed results $(p<0.0001-0.12$ according to test). There was a different result for $p$-mastigophores with ANOVA indicating no differences in length $(p=0.168)$ but discriminant analysis gave values of $p=0.002-$ 0.095 . Since we used separate whole polyps, the results do not necessarily indicate that method of fixation produces different degrees of shrinkage, and the three methods have not produced a consistent pattern for the three nematocyst types (Table 1); whether or not fixation method is important requires verification using a partitioned polyp fixed in three ways. The shrinkage caused by any method of fixation is, however, very marked in contrast to the fresh material, exploded or not (Table 1).

The remaining results, all based on preserved material, investigate differences between two sympatric species of Protopalythoa from the Great Barrier Reef and Fiji archipelago: Pr. mutuki and Pr. heliodiscus Ryland \& Lancaster (2003). Full details of the types of nematocyst occurring in these two species have been tabulated elsewhere (Ryland \& Lancaster, 2003: Tables 2 and 3). Since basitrichs are absent from Pr. heliodiscus, our present comparisons are restricted to holotrichs and $p$-mastigophores, which are abundant in the filaments of both species. Holotrich samples of $P r$. mutuki came from 12 polyps from five sites and of
Pr. heliodiscus from 11 polyps from seven sites; $p$ mastigophores of $\mathrm{Pr}$. mutuki came from seven polyps from five sites and of $\mathrm{Pr}$. heliodiscus from 11 polyps from seven sites (Table 1). Additionally, the clearly visible, sharply demarcated shaft in the capsule of $p$-mastigophores (Fig. 1G) can readily be measured, providing a third variable (Table 1).

Bivariate data are conveniently displayed in scattergrams (Figs 3 and 4) but not readily analysed by ANOVA or other univariate methods. Moreover, because two related variables are involved, regressions conform to Model II (Sokal \& Rohlf, 1995) and cannot be compared by ANCOVA, although comparisons between correlation coefficients are possible (Sokal \& Rohlf, 1995). This situation is discussed in detail, with respect to Acrozoanthus australiae, elsewhere (Ryland et al., 2003). Confidence ellipses (normally the $95 \%$ ) for each bivariate mean (see Sokal \& Rohlf, 1995) were calculated in BIOMstat and added to the Excel graph (Fig. 3); these ellipses are analogous to the confidence limits of a single mean (Fig. 4). The separation between the species based on filament holotrichs is particularly clear (Fig. 3), that for $p$-mastigophores less so, largely on account of an anomalous Pr. mutuki site (7 in Fig. 4). With two or three variables, discriminant analysis was used. As would be predicted from the plot, a comparison of sites shows significant differences between them. Although the pooled data show a strong difference between the two species $(p<0.0001$, reinforcing the validity of their separation based on other characters), the amount of overlap would make it difficult to identify any particular specimen on this criterion alone. Of 1606 individual capsule measurement sets, $\sim 16 \%$ of Pr. heliodiscus capsules would be confounded with $P r$. mutuki, and $\sim 26 \%$ of Pr. mutuki would be confounded with Pr. heliodiscus. While shaft length (as percentage of capsule length - arcsine transformed in the data analysis but not in the graph) - rather than capsule width is used for the $y$-variate in Fig. 4, because it appeared to be proportionally longer in $\mathrm{Pr}$. heliodiscus, the scattergram shows that this is true only for two sites (3 and 8 in Fig. 4).

The statistical analysis of the capsule measurements showed further complications. Just as we had found in Acrozoanthus australiae (Ryland et al., 2003), occasional populations of Pr. mutuki 


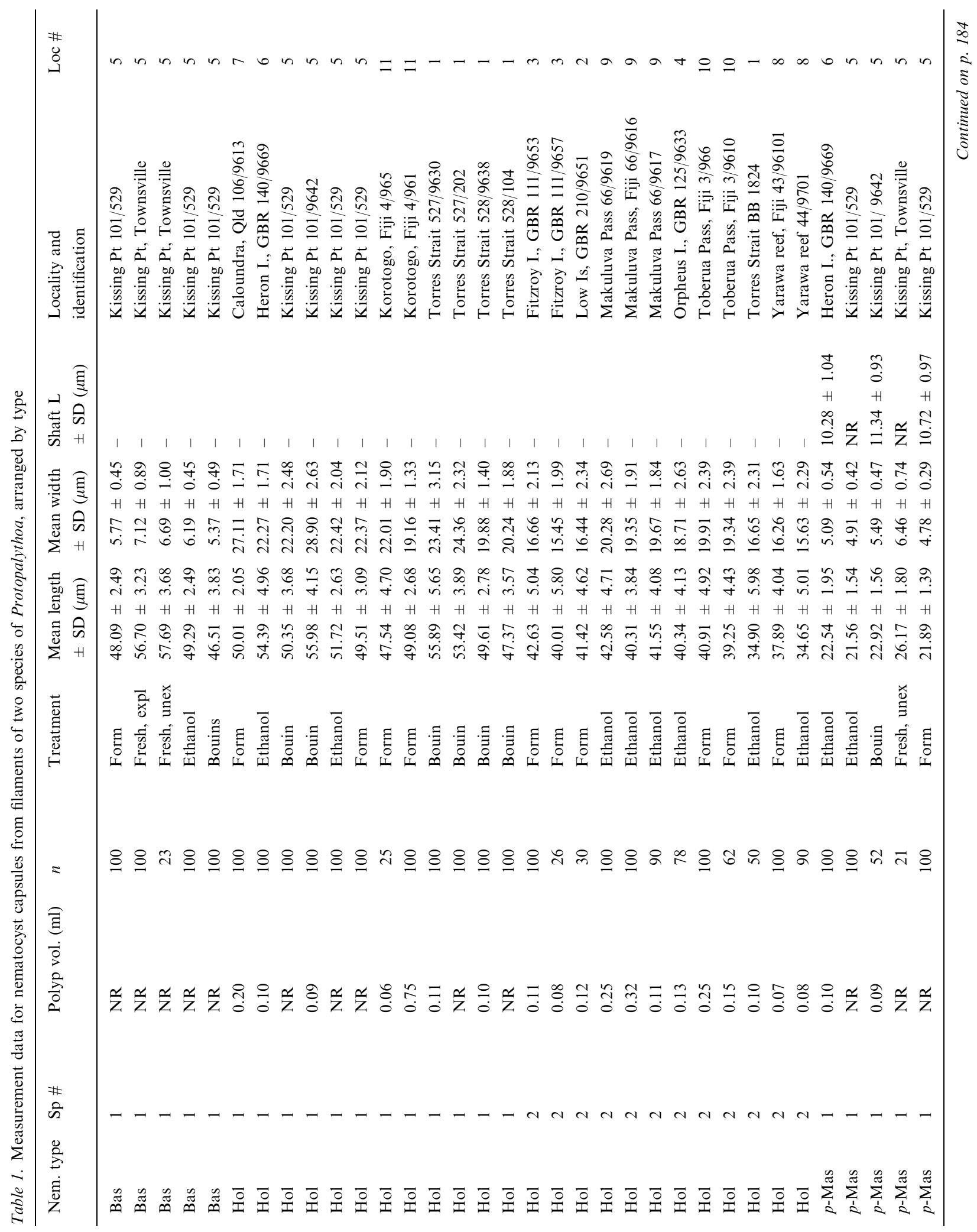




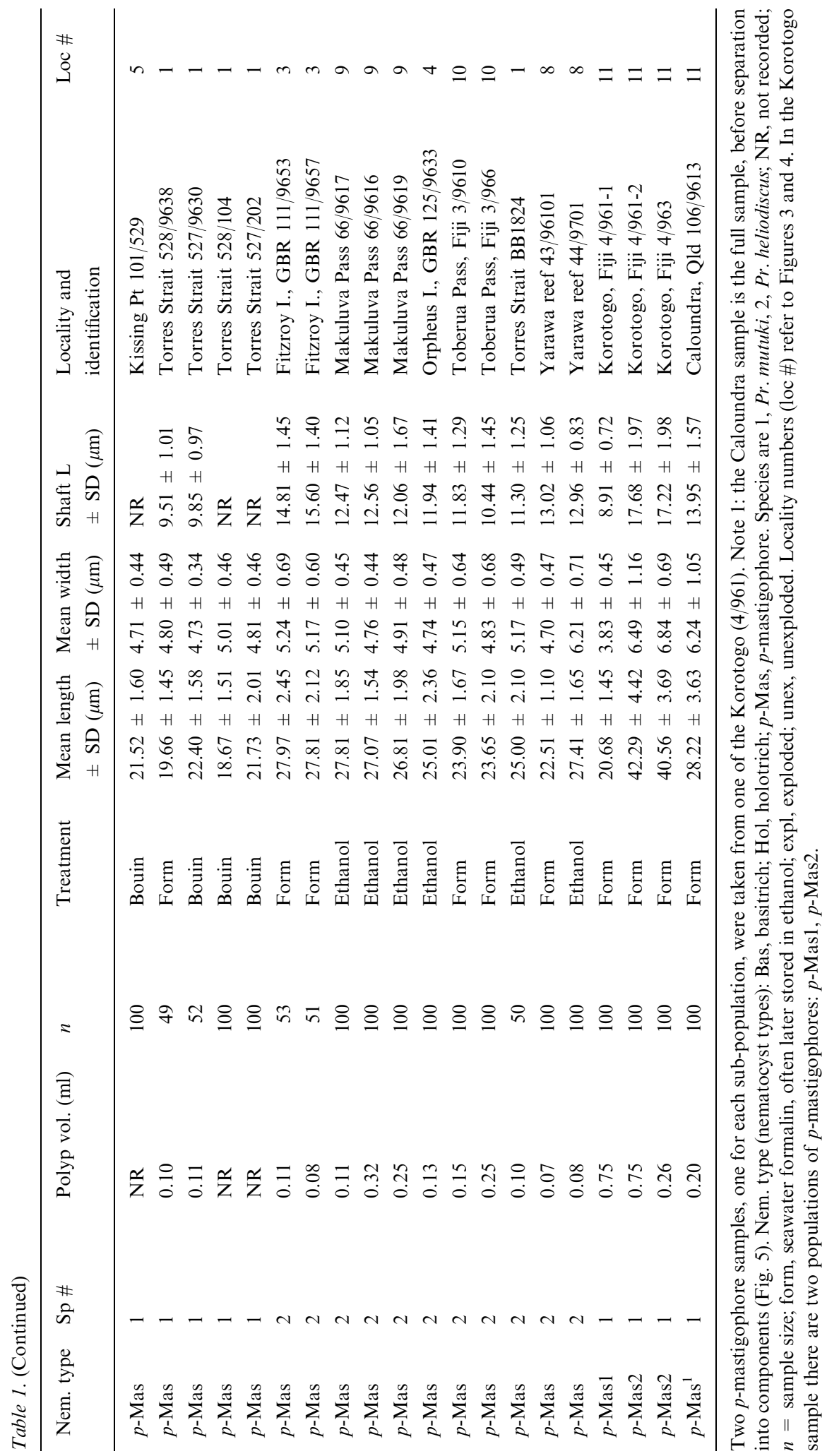




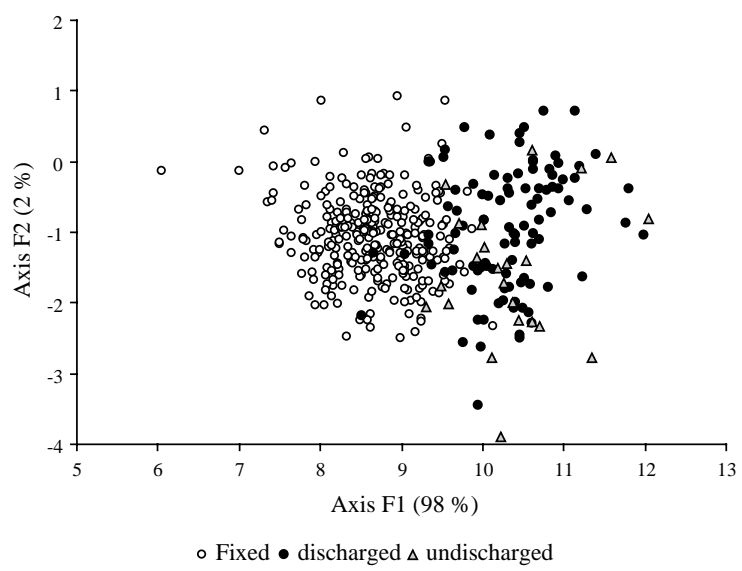

Figure 2. Discriminant analysis of capsule measurements (length, width) of filament basitrichs from Protopalythoa mutuki from the rocky intertidal of Kissing Point, Townsville. The comparison is between fixed material (Bouins fluid, $70 \%$ ethanol, and $4 \%$ sea water formaldehyde, $n=100$ each, with the samples merged), and un-fixed discharged $(n=100)$ and undischarged $(n=23)$ nematocysts (see text).

(but not of Pr. heliodiscus) contained two separate populations of $p$-mastigophores in their filaments. In one sample (Korotogo reef, Fiji; 11 in Fig. 4) the frequency distributions of capsule length were totally separated: $p_{1} \quad(n=96)$ mean 20.68 $(\mathrm{SD} \pm 1.45)$, range $16.58-24.02 \mu \mathrm{m} ; p_{2}(n=100)$ mean $42.95( \pm 3.07)$, range $35.96-50.61 \mu \mathrm{m}$. In a second population (Caloundra, coast of southern Queensland; 7 in Fig. 4), the length-frequency ranges overlap resulting in a bimodal distribution

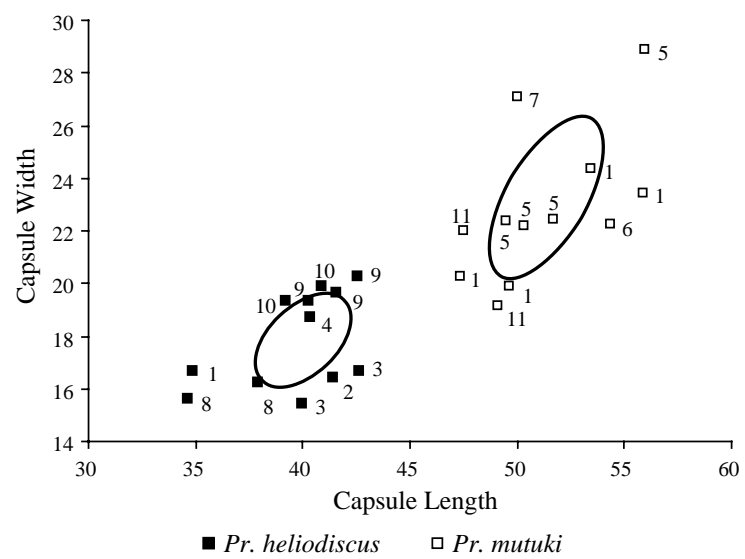

Figure 3. Scattergram, filament holotrich capsule sample means of width versus length in two Protopalythoa species, with ellipses indicating $95 \%$ confidence limits of the mean of means. Labels are localities (see Table 1 for key).

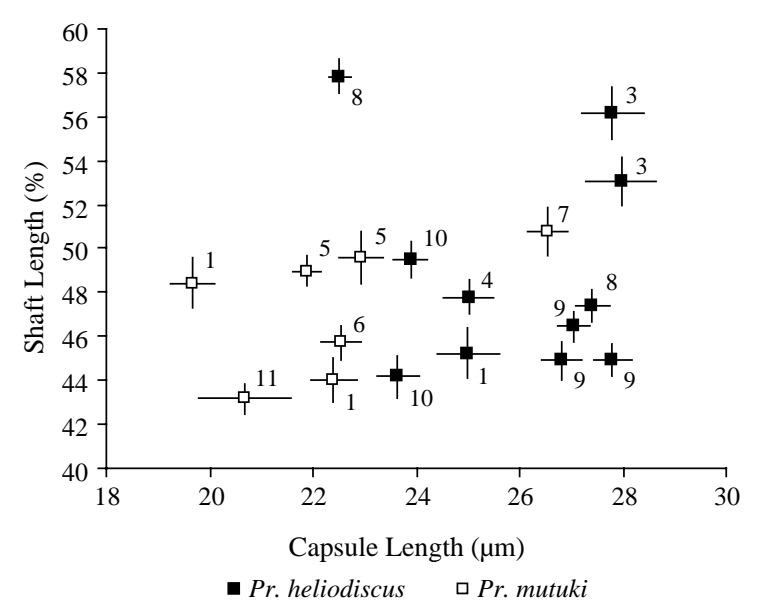

Figure 4. Scattergram, filament $p$-mastigophore capsule shaft length (as percentage of capsule length) versus capsule length sample means in two Protopalythoa species. Labels are localities (see Table 1 for key). Error bars are 95\% confidence limits.

(Fig. 5). In the diagram we have separated the two components by the standard graphical method (Harding, 1949; Cassie, 1954), reconstituting two separate population distributions (on the assumption of normality) using the proportions of the normal distribution curve found in standard statistical tables (e.g. Zar, 1996). We describe the

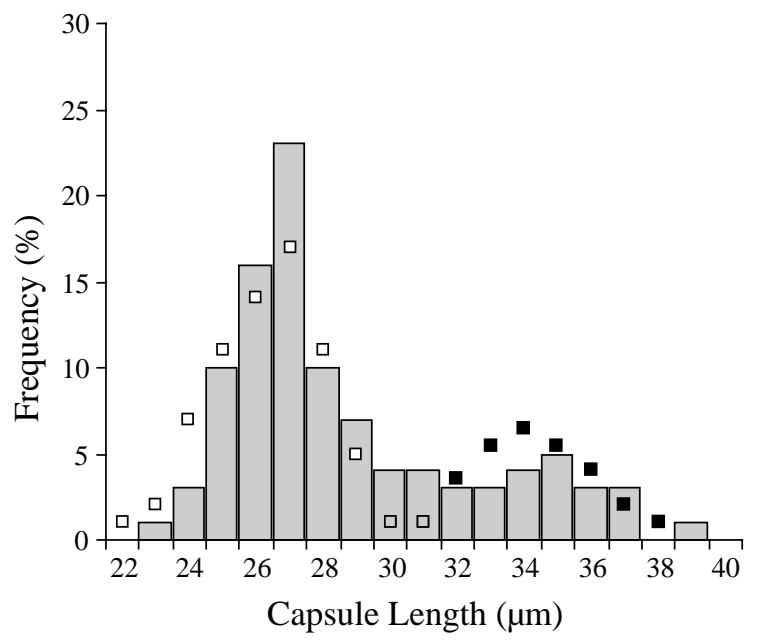

Figure 5. Analysis of bimodal distribution (filament p-mastigophores) of Protopalythoa mutuki from Caloundra, southern Queensland (grey bars), with the calculated distribution plots of the two sub-populations, $p_{1} \square$ and $p_{2} \boldsymbol{\square}$, assuming normal distributions (see text). The $30-31$ and $31-32 \mu \mathrm{m}$ bins contain not only the same number of original measurements but equal numbers of each sub-population. Arbitrary division has therefore been made at $31 \mu \mathrm{m}$ (see Fig. 6). 


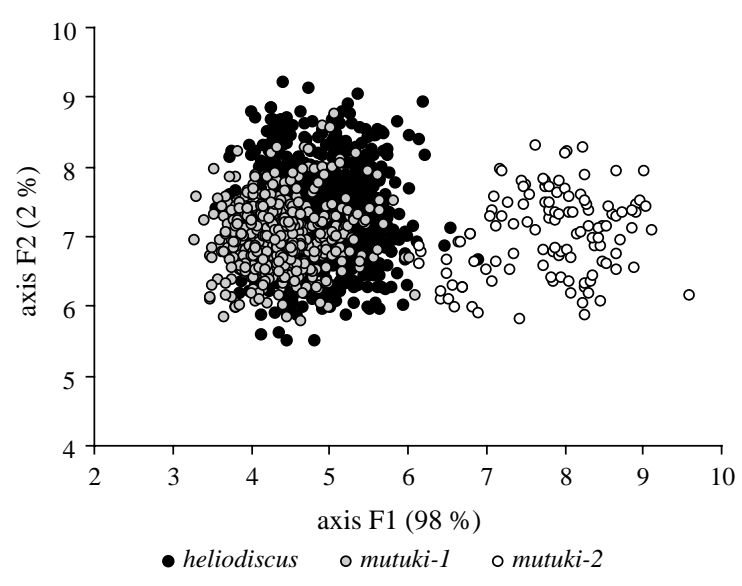

Figure 6. Discriminant analysis of filament $p$-mastigophore capsule measurements (length, width) from two species of Protopalythoa, using both $p_{1}$ and $p_{2}$ sub-populations found in Pr. mutuki (see Fig. 5 and text).

method fully elsewhere (Ryland et al., 2003). The method makes no subjective assumptions and shows, in this case, that there is a slight overlap at the tails of the distribution between 30 and $32 \mu \mathrm{m}$. Since the two relevant $1 \mu \mathrm{m}$ bins happened to contain the same number of measurements, and the predicted occurrence of the two types was approximately the same, an arbitrary separation was made at $31 \mu \mathrm{m}$. As seen in Figure 4, the point for sample 7 (based solely on the smaller, $p_{1}$, population) is still anomalously high; but the analysis establishes that this is not the result of sample contamination. The overall result of discriminant analysis, including all p-mastigophores (Fig. 6), shows a very strong separation of the $p_{2}$ size-group and would almost certainly have indicated if there had been contamination of any other $p_{1}$ samples.

Our analyses showed that several of the capsule length-frequency distributions departed from normality. One possible cause of this, as just indicated, would be the inclusion of a few measurements from a distinct, but smaller or larger, population. In other cases the cause of the departure remains unexplained. The overall problem of non-normality is not further considered here, having been thoroughly discussed elsewhere (Ryland et al., 2003).

\section{Discussion}

The greatest problem affecting our knowledge of nematocyst types within zoanthid higher taxa is the lack of ultra-structural studies, and hence ability to be able to differentiate types precisely; also, so few species have yet been studied in detail that generalization is unwise. Apart from the identity of 'atrichs', all zoanthid $b$-mastigophores and holotrichs II require SEM investigation. Treating nematocysts as populations depends on the availability of an image-analyser, since sample sizes are ideally at least 50 (Ryland et al., 2003). Digital images are more readily obtainable now but not all imaging software (as the University of Texas' shareware ImageTool) easily permits more than one measurement per object: we consider it desirable to measure as many capsule variables as practicable. Much information can be conveyed in bivariate scattergrams (Figs 3 and 4). The samples can be analysed by multivariate methods, such as discriminant analysis (Figs 2 and 6). The examples given in this paper demonstrate the utility of this approach in revealing differences between species, although inter-colony variation must also be properly evaluated. Discriminant analysis can help to resolve the identity of any particular collection with reference to known species and to decide whether two morphotypes constitute separate species even when capsule size ranges overlap (Fig. 6). The measurements from more than one nematocyst type can be combined in any analysis, increasing the resolving power. The erratic occurrence of differently sized sub-populations, particularly of $p$-mastigophores, is curious, observed in such unrelated species as Acrozoanthus australiae (Ryland et al., 2003) and Protopalythoa mutuki. Normality must be checked, and bimodal distributions separated into component parts.

Substantial shrinkage of capsules during fixation, such as we have demonstrated, would be expected but the effects of different fixation and preservation protocols - which we have been unable to resolve here - require further investigation. We have not considered in this paper any correlation of nematocyst size with polyp size, a very real consideration in zoanthids, but draw attention to the inconsistent patterns found in Acrozoanthus australiae (Ryland et al., 2003): polyp size must always be recorded. So far as species descriptions are concerned, size ranges (i.e. minimum to maximum) should be replaced, or at least supplemented, by calculated statistical parameters. 


\section{References}

Carlgren, O., 1940. A contribution to the knowledge of the structure and distribution of the cnidae in the Anthozoa. Kungliga Fysiografiska Sälskapets i Lund Förhandlingar. 51: $1-62$.

Cassie, R. M., 1954. Some uses of probability paper in the analysis of size frequency distributions. Australian Journal of Marine and Freshwater Research 5: 513-522.

Chintiroglou, C. \& M. Simsiridou, 1997. Biometric investigations on the cnidae of the sea anemone Actinia equina mediterranea form I Schmidt, 1971. Proceedings of the Sixth International Conference on Coelenterate Biology, Nationaal Natuurhistorisch Museum, Leiden: 101-108.

Cutress, C. E., 1955. An interpretation of the structure and distribution of cnidae in Anthozoa. Systematic Zoology 4: $120-137$.

England, K. W., 1987. Certain Actiniaria (Cnidaria, Anthozoa) from the Red Sea and tropical Indo-Pacific Ocean. Bulletin of the British Museum (Natural History), Zoology 53: 205292

England, K. W., 1991. Nematocysts of sea anemones (Actiniaria, Ceriantharia and Corallimorpharia: Cnidaria): nomenclature. Hydrobiologia 216/217: 691-697.

Fahmy, T. \& A. Aubry, 2002. XLstat. Addinsoft, Paris.

Fautin, D. G., 1988. Importance of nematocysts to actinian taxonomy. In Hessinger, D. A. \& H. M. Lenhoff (eds), The Biology of Nematocysts. Academic Press, London: 487-500.

Harding, J. P., 1949. The use of probability paper for the graphical analysis of polymodal frequency distributions. Journal of the Marine Biological Association of the United Kingdom 28: 141-153.

Hidaka, M., 1992. Use of nematocyst morphology for taxonomy of some related species of scleractinian corals. Galaxea 11: $21-28$.

Pires, D. O. \& F. B. Pitombo, 1992. Cnidae of the Brazilian Mussidae (Cnidaria: Scleractinia) and their value in taxonomy. Bulletin of Marine Science 51: 231-244.
Rohlf, F. J. \& D. E. Slice, 2002. BIOMstat: Statistical Software for Biologists. Applied Biostatistics, Port Jefferson, NY.

Ryland, J. S. \& J. E. Lancaster, 2003. Revision of methods for separating species of Protopalythoa (Hexacorallia: Zoanthidea) in the tropical West Pacific. Invertebrate Systematics 17: 407-428.

Ryland, J. S., M. M. Brasseur \& J. E. Lancaster, 2003. Use of cnidae in taxonomy: implications from a study of the cnidome of Acrozoanthus australiae (Hexacorallia: Zoanthidea). Journal of Natural History 38: 1193-1223.

Schmidt, H., 1972. Die Nesselkapseln der Anthozoen und ihre Bedeutung für die phylogenetische Systematik. Helgoländer Wissenschaftliche Meeresuntersuchungen 23: 422-458.

Schmidt, H., 1974. On evolution in the Anthozoa. Proceedings of the Second International Symposium on Coral Reefs 1: $533-560$.

Sokal, R. R. \& F. J. Rohlf, 1995. Biometry. W. H. Freeman, San Francisco.

Updegraff, G., 1990. MeasurementTV. DataCrunch, San Clemente.

Weill, R., 1934. Contribution a l'étude des cnidaires et de leurs nematocystes. Travaux de la Station Zoologique de Wimereux 10-11: 1-702.

Westfall, J. A., 1965. Nematocysts of the sea anemone $\mathrm{Me}$ tridium. American Zoologist 5: 377-393.

Williams, R. B., 1996. Measurements of cnidae from sea anemones (Cnidaria: Actiniaria): statistical parameters and taxonomic relevance. Scientia Marina 60: 339-351.

Williams, R. B., 1998. Measurements of cnidae from sea anemones (Cnidaria: Actiniaria), II: further studies of differences amongst sample means and their taxonomic relevance. Scientia Marina 62: 361-372.

Williams, R. B., 2000. Measurements of cnidae from sea anemones (Cnidaria: Actiniaria), III: ranges and other measures of statistical dispersion, their interrelations and taxonomic relevance. Scientia Marina 64: 49-68.

Zar, J. H., 1996. Biostatistical Analysis. Prentice Hall, Upper Saddle River, NJ. 